\title{
A sexualidade e o tabagismo
}

Heitor Hentschel*

É impossível nos dias de hoje e à luz dos conhecimentos de patologias causadas pelo tabagismo, não correlacioná-los com as alterações do comportamento e fisiologia sexual e com os prejuízos na reprodução humana.

O tabagismo é uma doença crônica que afeta todos os órgãos da economia humana e também compromete a sexualidade que é prejudicada em maior ou menor proporção, mais cedo ou mais tarde, direta ou indiretamente.

Nos dizeres impressos pelo Ministério da Saúde junto às propagandas de cigarro, há uma que claramente faz menção de que "O CIGARRO CAUSA IMPOTÊNCIA SEXUAL". Os fumantes que sabem ler não acreditam que possa ser verdade. Pensam que é apenas um aviso igual ao que as mães diziam quando assustavam as crianças com o "bicho-papão".

Será que realmente o tabagismo prejudica o desempenho sexual? Como isto ocorre? Como começa? E nas mulheres, o tabagismo causa algum problema sexual ou de reprodução humana?

O tabagismo era considerado um importante fator de aproximação sexual entre as pessoas. Durante toda a década de 40, 50 e 60 o mundo foi bombardeado pelas películas de Hollywood. Víamos como os artistas se

* Ginecologista, sexólogo. Membro da diretoria da SBRASH. 
comportavam e como aconteciam a iniciação dos encontros amorosos. Todos guardamos na lembrança os glamurosos artistas, machões como Humphrey Bogart ou Clark Gable que quase sempre queriam conquistar. Quem não lembra da famosa cena de Casablanca, no bar enfumaçado de Sam quando mal se conseguia ver as pessoas? Talvez a famosa melodia "Smoke get's in your eyes" fosse mais devido à fumaça do cigarro do que à emoção da situação. No filme Gilda com Rita Hayworth ela usava uma longa e fálica piteira mostrando-se sedutora e desejada. Boa parte das mulheres do mundo mundano passaram à imitá-la.

Os adolescentes na década de 50 e 60 tinham como um dos ideais da vida poder fumar tranqüilos na frente dos pais.

Àquela época existia um charme, um ritual de gestos bem estudados para se fumar. Por exemplo, chegar num barzinho ou na mesa de um restaurante e retirar pausadamente o maço de Minister do bolso interno do paletó e jogá-lo displicentemente em cima da mesa e, incontinente, colocar o isqueiro Zippo ou Dupont à disposição de quem quisesse... Bater o cigarro na ponta da mesa ou mesmo em cima da unha do polegar esquerdo para socar o fumo e acendê-lo com maestria era uma demonstração de elegância e fatualidade.

Quando alguma mulher se aproximava do jovem querendo conversa, pedia: "Me dá um cigarro?" "Me paga uma cuba?"

Quase todos os adolescentes fumavam. Era moda, era bonito. Apenas se repetia o comportamento dos artistas e sentiam-se conquistadores e charmosos como eles... Todos os filmes de guerra mostravam os heróis americanos fumando e dando cigarros para a recém liberta população francesa e italiana. Fumar era um gesto de heroísmo.

O que se ficou sabendo mais tarde foi a morte de Humphrey Bogart de câncer de pulmão e de Clark Gable de infarto do miocárdio.

$\mathrm{O}$ jovem quer fumar para se sentir mais adulto, mais maduro e mais hábil na arte de conquistar. Em determinada conferência foi mencionado que os meninos de uma comunidade latino-americana iniciavam o tabagismo porque queriam ter a voz rouca e grossa dos artistas.

As meninas iniciavam o tabagismo para se mostrarem liberadas. Sempre era uma porta aberta para iniciar um diálogo. Entretanto uma mulher não podia fumar na rua. Só as prostitutas podiam fazê-lo. As mulheres fumavam em casa, em mesas de bar ou de restaurantes. Muitas mulheres entravam em lojas, fingiam ver um ou outro artigo apenas para poder fumar, já que lhes era proibido, pela moral vigente, de fumar nas ruas ou calçadas. Mais tarde, este comportamento foi assumido e hoje pode-se ver senhoras fumando que ninguém ousa duvidar de sua honorabilidade.

$\mathrm{O}$ que não se sabia era que assumindo o comportamento dos artistas, estava-se obedecendo uma ordem que era imposta sutil e deliberadamente pela indústria tabageira. Era o "merchandising" em ação. Sequer era conhecida a palavra, o que dizer o significado. 
Mas se os jovens do terceiro mundo repetiam o comportamento dos artistas, também os jovens americanos faziam igual. E em maior intensidade.

Muito antes do que os subdesenvolvidos, foram os próprios americanos que anunciaram os malefícios do tabagismo e que mostraram a fisiologia sexual comprometida.

É importante saber e repetir que a relação sexual envolve intensa movimentação e crescente e importante tensão muscular.

Durante a fase de excitação e à medida que se aproxima do clímax, alguns parâmetros orgânicos se modificam. Por exemplo:

FREQÜÊNCIA CARDÍACA: Aumenta progressivamente até atingir 100, 175 na fase de excitação e no orgasmo podem chegar a $200 \mathrm{bpm}$.

FREQÜÊNCIA RESPIRATÓRIA: Ocorre hiperventilação com aumento progressivo da freqüência respiratória, podendo atingir acima de $60 \mathrm{bpm}$. Volume de ar corrente aumenta, ocorre dilatação das narinas para captar melhor $\mathrm{o}$ ar e sentir melhor os odores sexuais.

PRESSÃO ARTERIAL: A pressão arterial, como no exercício, tem a diastólica diminuída e a sistólica elevada podendo chegar a 180 por 30 milímetros de mercúrio. Lentamente, após o orgasmo ou a parada da movimentação, os parâmetros voltam às condições basais.

Porém, antes de ocorrer a relação, há necessidade de excitação sexual. No homem a excitação é traduzida pela ereção peniana e na mulher pela lubrificação vulvo-vaginal.

Estes dois fenômenos têm a mesma origem, os mesmos neuro-transmissores e as mesmas vias nervosas e vasculares.

A ereção masculina é muito melhor estudada do que a lubrificação feminina. Por outro lado, a incapacidade de conceber na mulher é melhor estudada do que a capacidade fecundadora masculina.

Se ocorrer alguma alteração nervosa ou vascular, a obtenção da ereção ou da lubrificação pode ser prejudicada, ou dificultada. A intensa vasodilatação e congestão pélvica necessária para a ereção exige boa vascularização e permeabilidade arterial. A excitação sexual necessita de bons nervos condutores de estímulos. Caso estes nervos estejam comprometidos, a condução nervosa se faz deficientemente, não ocorrendo o feed-back necessário e auto incrementado.

As dificuldades de ereção e de relacionamento sexual são progressivas e lentas. Ocorrem lentamente e normalmente com o passar dos anos.

Como a atividade sexual é um misto de emoção e fatores orgânicos, quando ocorrem falhas sexuais, a tendência inicial é atribuir as falhas ou deficiências eventuais ao emocional ou à deficiência diádica. "Deve ser algo que comi e não me fez bem." "Estou preocupado com a prestação da casa." "Esta mulher está ficando velha." Como as falhas são insidiosas, as desculpas ficam mais amiudadas, até que chega a um ponto de exigir aten- 
ção médica. Aí, geralmente é tarde para uma recuperação. Muito raramente o homem procura atenção médica por vontade própria. Lentamente vai se esquivando do relacionamento sexual, atribuindo à idade ou à mulher ou aos estímulos inadequados a incapacidade eretiva e orgástica. Quando percebe que não tem ereção com mais ninguém é que procura assistência médica.

O tabagismo é a causa mais importante e freqüente de incapacidade copulativa ou de ereção e isto é igualmente encontrado nos dois sexos, apenas no homem é melhor estudado. $\mathrm{O}$ tabagismo age em vários órgãos e sistemas necessários ao relacionamento sexual:

1. DEFICIÊNCIA RESPIRATÓRIA: A progressiva diminuição da capacidade pulmonar faz com que o fumante tenha menor movimentação. Evita movimentos copulativos mais amplos e demorados. $\mathrm{O}$ aumento da frequiência respiratória e o aumento do volume do ar corrente pode ocasionar acessos de tosse com conseqüente expectoração abundante. É evidente que não existe nada mais repugnante que um beijo depois de um acesso de tosse produtiva...

2. DEFICIÊNCIA CARDÍACA: As dores anginosas, despertadas pelo movimento e pelo aumento da frequêencia cardíaca são absolutamente proibitivas da continuidade do relacionamento sexual. As causas ou fatores predisponentes do infarto do miocárdio são exatamente as mesmas causas e fatores predisponentes da impotência sexual:

Idade

Sedentarismo

Tabagismo

Alterações lipídicas

Hipertensão arterial, diabetes, doenças crônico-degenerativas

Alterações emocionais.

O infarto do miocárdio e a impotência de origem orgânica constituem expressão de alteração vascular.

Cerca de sessenta por cento dos homens (60\%) que tiveram infarto desenvolvem impotência sexual e quase cem por cento das esposas $(100 \%)$ dos homens infartados apresentam anorgasmia após o infarto de seu marido.

As medições usuais para controle da hipertensão arterial são quase sempre inibidoras da ereção. Bem como os tranqüilizantes, medicamentos para emagrecer e vaso-dilatadores.

3. DEFICIÊNCIA HORMONAL: O tabagismo continuado leva à diminuição progressiva e antecipada da produção hormonal das gônadas. Na mulher esta diminuição é mais evidente pela antecipação da menopausa e dos comemorativos que ela trás. No homem por não existir a andropausa, a antecipação da diminuição dos hormônios sexuais é desapercebida. 
Há diminuição do interesse sexual, de sonhos eróticos, do ímpeto e da freqüência copulativa.

Na mulher tabagista a menopausa é antecipada em cerca de dois anos. $\mathrm{O}$ deficiente aporte de sangue nos ovários determina diminuição da função ovariana, com parada da maturação folicular e mais tarde com diminuição da produção hormonal. Com a diminuição do nível de estrogênio, ocorrem as clássicas e conhecidas alterações físicas da mulher como alteração da deposição das gorduras, diminuição da resposta vulvo-vaginal para exudação volvo-vaginal, diminuição da espessura das paredes vaginais e vulvares, ocasionando o ato sexual desagradável e doloroso. A fonte interna feminina de testosterona é predominantemente do folículo ovariano. Com a parada da maturação folicular, ocorre diminuição da produção de testosterona. Esta diminuição determina a diminuição do desejo sexual. Algum tempo mais tarde ocorre a produção de androgênios de origem nas supra renais. Porém este androgênio promove mais virilização do que desejo sexual.

A diminuição dos hormônios femininos acrescido à diminuição de perfusão da pele, determina aumento da viscosidade da pele viscosa com diminuição da temperatura.

A osteoporose é mais freqüente entre fumadoras. Por outro lado, face a ação antiestrogênica do tabagismo, há menor incidência de miomatose e câncer de endométrio.

4. DEFICIÊNCIA VASCULAR: As alterações nos calibres das artérias correm paralelo com as alterações de pressão arterial ou de vascularização miocárdica. No fumante ocorre nítida diminuição do calibre as artérias pudendas, que são ramos das ilíacas internas. A ereção leva mais tempo para ser conseguida e, como os movimentos coitais exigem perfusão dos músculos pélvicos e das pernas, há diminuição do aporte sangüíneo para as artérias pudendas, com perda da ereção tão pronto se iniciam os movimentos coitais.

O uso de substâncias que facilitam a ereção (Sildenafil e Alprostadil), podem ser contra-indicados. O Sildenafil é contra-indicado em pacientes com deficiência vascular que fazem uso concomitante de nitratos e deve ser usado com cautela em pacientes com isquemia coronária aguda, angina instável ou hipertensão controlada com múltiplos regimes medicamentosos.

5. ALTERAÇÃO NA CONDUÇÃO NERVOSA: Os nervos necessários à função sexual são os pudendos. Estes se dividem em três ramos e são responsáveis pela sensibilidade dos órgãos sexuais. $\mathrm{O}$ tabagismo não interfere diretamente na condução nervosa porém é fator coadjuvante importante na presença de alcoolismo e no diabete, situações estas que podem ocasionar alteração na condução nervosa. Quando se associam lesões vasculares à deficiências nervosas, a incapacidade eretiva se instala mais precocemente. $\mathrm{O}$ alcoolismo, embora não seja assunto neste momento, tem marcada ação 
no desempenho sexual, e a alteração geralmente se inicia com dificuldade em obtenção.do orgasmo.

$\mathrm{O}$ tabagismo tem múltiplas superfícies de contato com a sexualidade pois primitivamente altera as condições de vida. Muitas neoplasias são mais freqüentes em fumantes. Pelo fato das neoplasias comprometerem a vida do indivíduo, é fácil depreender que esta agressão à vida tenha repercussões na sexualidade. $\mathrm{O}$ câncer de colo de útero, por exemplo, é mais freqüente em tabagistas do que em não tabagistas. Sendo necessária a extirpação do útero e rádio e quimioterapia é fácil concluir na alteração da função sexual. Outros tumores são igualmente inibidores da atividade sexual como câncer de língua, de laringe, pulmão e outros.

As doenças cárdio-cérebro-vasculares são mais comuns em fumantes. Um seqüelado de acidente vascular pode ficar impedido sexualmente.

Na reprodução humana a lista de complicações ou de alteração de funcionalidade decorrente do tabagismo são inúmeras:

1. Diminuição da fertilidade. Um dos componentes da fumaça do cigarro é a acroleina, substância capaz de diminuir a motilidade das estruturas ciliares. A movimentação dos espermatozóides são tipicamente ciliares. As trompas de Fallopio são revestidas por cílios que são responsáveis pelo transporte do folículo e do ovo. Sob ação da acroleína este movimento ciliar está diminuído ou ausente.

2. As fumantes tem maior incidência de gravidez ectópica. Talvez a gênese seja devida ao déficit do movimento ciliar de transporte do ovo.

3. Existe um marcado aumento na incidência de abortamentos espontâneos.

4. As tabagistas têm menor duração da gestação com evidente aumento na incidência de partos prematuros. Uma explicação poderia ser a diminuição da perfusão placentária ocasionada pela ação vasoconstictora da nicotina ou pelo aumento de carbohemoglobina fetal e materna.

5. Há diminuição do peso fetal de até $\mathbf{2 0 0}$ gramas. Talvez pelo mesmo mecanismo acima.

6. Há incidência maior de placentas com anomalia de inserção. Talvez pela diminuição da velocidade de transporte ciliar, chegando o ovo na cavidade uterina quando o endométrio já não esteja em sua melhor condição.

7. Nítido aumento de descolamentos prematuros de placenta normo-inserida.

8. Diminuição da duração da amamentação com introdução precoce de alimentação artificial. As mamas são glândulas sudoríparas modificadas e excretam também nicotina e seus metabólitos como a cotinina. 
9. Os filhos de casais fumantes apresentam maior freqüência de doenças respiratórias e de otites com diminuição do desenvolvimento pondo-estatural.

10. Os filhos de fumantes apresentam desenvolvimento intelectual deficiente em comparação com o desenvolvimento de outras crianças de não-fumantes. Há atraso em iniciar a caminhar e a falar. Há nítida diminuição de capacidade de raciocínio empírico, como matemática.

\section{BIBLIOGRAFIA RECOMENDADA}

1. APLETON \& LANGE. Current - Obstetrics \& Gynecologic Diagnosis \& Treatment. Stamford CT, 1994.

2. APLETON \& LANGE. Current-Medical Diagnosis \& Treatment. Stamford CT, 1998.

3. CAVALCANTI \& CAVALCANTI. Tratamento clínico das inadequações sexuais. São Paulo: Roca, 1992.

4. FREITAS, Fernando et alli. Rotinas em obstetrícia. Porto Alegre: Artes Médica, 1997.

5. HALBE, Hans W. Tratado de ginecologia. São Paulo: Roca, 1999.

6. MASTERS, William H. e JOHNSON, Virginia E. A resposta sexual humana. São Paulo: Roca, 1984.

7. MORGENTALER, Abraham. The Lancet. v. 354 (9191) pp. 1713-1718.

8. RIORDAN, Jan. Breastfeeding and human lactation. Boston: Jones \& Bartlett, 1993.

9. ZUGAIB, Marcelo. Medicina fetal. São Paulo: Atheneu, 1998. 